T. 2, № 2, 2020

УДК 621.3.061; 621.3.051.2

К. Б. Покровський

Національний університет «Львівська політехніка», кафедра електроенергетики та систем управління

Email: kostiantyn.b.pokrovskyi@lpnu.ua

O. I. Маврін

Національний університет «Львівська політехніка», кафедра електроенергетики та систем управління

Email: olherd.i.mavrin@lpnu.ua

В. П. Олійник

Національний університет «Львівська політехніка», кафедра електроенергетики та систем управління

Email: volodymyr.p.oliinyk@lpnu.ua

\title{
СТАТИЧНІ ХАРАКТЕРИСТИКИ ПОТУЖНОГО АСИНХРОНІЗОВАНОГО ТУРБОГЕНЕРАТОРА В АСИНХРОННОМУ РЕЖИМІ
}

https://doi.org/

(С) Покровський К. Б., Маврін О. І., Олійник В. П., 2020

Існуючий стан енергосистеми України характеризусться широким використанням ліній електропересилання 3 класами напруги 330 та 750 кВ. Зарядна потужність таких повітряних ліній доволі значна, що генерує в мережу значні обсяги реактивної потужності, які проявляють себе особливо в години зниження навантаження в енергосистемі помітними зростаннями рівнів напруг. Надлишки реактивної потужності впливають на режими роботи регуляторів збудження синхронних генераторів звуженням їх робочого діапазону. За таких умов модернізація або реконструкція електростанцій повинна враховувати можливість розв'язання цілого комплексу задач, що пов'язані з раціоналізацією витрати електроенергії та енергоресурсів, врахуванням зв'язку режимів електростанції 3 режимами споживачів електроенергії, що пов'язане 3 надлишками реактивної потужності на шинах електростанцій залежно від ролі станції в енергосистемі, підвищенням надійності роботи обладнання станції, збільшенням станційної межі динамічної стійкості, зниженням необхідного аварійного резерву енергосистеми тощо. В такому випадку набувас актуальності проблема застосування на електростанціях поряд 3 традиційними синхронними генераторами i асинхронізованих турбогенераторів, що підвищус надійність і якість роботи електростанції завдяки більшійефективності асинхронізованого генератора із забезпеченням стійкості i додатковим запасом щодо режиму споживання реактивної потужності. 
Широке впровадження асинхронізованих турбогенераторів в енергосистемі України може дозволити вирішити проблеми надлишкової реактивної потужності на шинах електростанцій в години зниження навантаження в енергосистемі за рахунок можливості глибокого споживання надлишків асинхронізованими генераторами, що сприятиме стабілізації в допустимих межах рівнів напруг.

Додатково слід зазначити, що широке впровадження АСТГ дасть змогу вплинути на проблему звуження регулювального діапазону автоматичних регуляторів збудження синхронних генераторів, які в умовах надлишкової реактивної потужності вимушено переходять у режими роботи, що близькі до споживання реактивної потужності синхронним генератором і обмежені дісю захистів.

У роботі наведено результати розрахунків координат асинхронних режимів асинхронізованого турбогенератора на основі параметрів заступної схеми. Показано особливості координат асинхронних режимів - асинхронні характеристики асинхронізованого турбогенератора потужністю 1000 МВт. Такі характеристики дозволяють розглядати можливість застосування асинхронного режиму потужного асинхронізованого генератора в умовах енергоблоку АЕС за умови розширення добового регулювального діапазону обладнання блоку.

Ключові слова: асинхронізований генератор, асинхронний режим, реактивна потужність, режим генератора.

\section{Постановка проблеми}

Особливістю електроенергетики України $є$ широке використання ліній електропересилання (ЛЕП) класами напруги 330 та 750 кВ. Зарядна потужність таких ЛЕП доволі значна. В таких умовах модернізація або реконструкція електростанцій повинна враховувати можливість розв'язання цілого комплексу задач, що пов'язані з раціональним використанням електроенергії та енергоресурсів, урахуванням зв'язку режимів електростанції з режимами споживачів електроенергії, що пов'язане 3 надлишками реактивної потужності на шинах електростанцій залежно від ролі станції в енергосистемі, підвищенням надійності роботи обладнання станції, збільшенням станційної межі динамічної стійкості, зниженням необхідного аварійного резерву енергосистеми, тощо [1]. В такому випадку набуває актуальності проблема застосування на електростанціях поряд 3 традиційними синхронними генераторами і асинхронізованих турбогенераторів (АСТГ), що підвищує надійність і якість роботи електростанції за рахунок більшої ефективності генератора із забезпеченням стійкості і додатковим запасом за режимом споживання реактивної потужності.

Застосування АСТГ на електростанціях в Україні було запроваджено у 1985 році пуском у дослідну експлуатацію першого в світі АСТГ. Характерним показником успішності такого рішення є багаторічна робота АСТГ-200 у складі Бурштинської ТЕС, зокрема у паралельному режимі 3 енергосистемою Свросоюзу [2].

Широке впровадження АСТГ в енергосистемі України дасть змогу вирішити проблеми надлишкової реактивної потужності на шинах електростанцій в години зниження навантаження в енергосистемі завдяки можливості глибокого споживання цих надлишків асинхронізованими генераторами, що сприятиме стабілізації в допустимих межах рівнів напруг.

Додатково слід зазначити, що впровадження АСТГ дасть змогу вплинути на проблему звуження регулювального діапазону автоматичних регуляторів збудження синхронних генераторів, які в умовах надлишків реактивної потужності вимушено переходять у режими роботи, що близькі до споживання реактивної потужності і обмежені дією захистів [2]. 


\section{К. Б. Покровський, О. І. Маврін, В. П. Олійник}

\section{Актуальність дослідження}

Значної уваги в Україні і в світі приділено дослідженням АСТГ потужністю 200 МВт, що вперше було впроваджено на Бурштинській ТЕС у 1985 році [1-4 та ін.]. Однак, з розвитком енергосистеми та сучасних технологій, з'являються нові області застосування потужніших асинхронізованих генераторів.

Значний вплив атомних електростанцій (AEC) України на режими енергосистеми визначається, разом з іншим, появою надлишків реактивної потужності через потребу у стабільних рівнях напруг на шинах цих станцій, що не беруть участі у добовому регулюванні системних навантажень, але комутовані потужною мережею повітряних ліній класом напруги 750кВ, яка і $є$ найбільшим джерелом надлишків реактивної потужності. Результати досліджень асинхронних характеристик потужних АСТГ, що можуть бути застосовані в умовах АЕC або відсутні, або не опубліковані у вигляді реальних характеристик асинхронного режиму генератора. У зв'язку з цим стає актуальним отримання асинхронних характеристик потужних АСТГ з метою подальшого аналізу можливостей використання таких генераторів в умовах АЕC.

\section{Формулювання мети і завдань статті}

Метою і завданням роботи $є$ отримання графічних залежностей координат асинхронних режимів потужного АСТГ потужністю 1000 МВт, параметри якого визначено в [6]. Отримані результати дозволять застосувати їх під час інженерних оцінок можливостей асинхронного режиму потужного АСТГ в умовах схем видачі потужності АЕС.

\section{Аналіз останніх досліджень і публікацій}

У роботах $[1,2]$ наведено характеристики асинхронних режимів АСТГ потужністю 200 МВт. Параметри АСТГ потужністю 1000 МВт наведено в [6], а спробу оцінювання роботи АСТГ в умовах AEC здійснено в [3,4]. Однак асинхронні характеристики потужного генератора типу АСТГ відсутні у відкритих джерелах.

\section{Виклад основного матеріалу}

Асинхронний режим АСТГ має ряд особливостей порівняно з асинхронізованим режимом. Асинхронізований турбогенератор в асинхронному режимі з закороченими, розімкненими чи замкненими на додатковий опір обвитками збудження може тривало нести активне навантаження при споживанні реактивного навантаження, що обмежується лише струмом статора та потужністю турбіни, однак найефективнішим є режим короткозамкнених обвиток збудження [6]. При цьому цей режим не супроводжується властивими синхронній машині коливаннями параметрів режиму i сприяє стійкій роботі електростанції загалом.

Основним завданням АСТГ крім генерації активної потужності є компенсація надлишків реактивної потужності, що виникають в енергосистемі в години провалів графіка навантаження, зокрема в нічні години. Саме в цей період графіка навантаження АСТГ в асинхронному режимі може споживати реактивну потужність і нести дещо знижене активне навантаження. Якщо врахувати, що цей режим може бути охарактеризований як такий, що має більшу надійність роботи через відсутність системи збудження, то в результаті наведених міркувань можна зробити висновок про можливість використання асинхронного режиму АСТГ як додаткового робочого режиму в умовах AEC.

Асинхронний режим АСТГ-1000 супроводжується глибоким споживанням реактивної потужності, що обмежується максимальним струмом статора генератора на потужністю турбіни. Отримання асинхронних характеристик генератора можна реалізувати на основі системи рівнянь узагальненого електромеханічного перетворювача [4] вигляду: 


$$
\left\{\begin{array}{l}
-u_{d}=(r+p x) i_{d}+p x_{a d}\left(i_{f d}+i_{r d}\right)+x i_{q}+x_{a d}\left(i_{f q}+i_{r q}\right) \\
-u_{d}=(r+p x) i_{d}+p x_{a d}\left(i_{f d}+i_{r d}\right)+x i_{q}+x_{a d}\left(i_{f q}+i_{r q}\right) \\
-u_{f q}=\left(r_{f}+p x_{f}\right) i_{f q}+p x_{a d}\left(i_{q}+i_{r q}\right)-s\left(x_{f} i_{f d}+x_{a d}\left(i_{d}+i_{r d}\right)\right) \\
-u_{f d}=\left(r_{f}+p x_{f}\right) i_{f d}+p x_{a d}\left(i_{d}+i_{r d}\right)-s\left(x_{f} i_{f q}+x_{a d}\left(i_{q}+i_{r q}\right)\right) \\
0=\left(r_{r}+p x_{r}\right) i_{r q}+p x_{a d}\left(i_{q}+i_{f q}\right)-s\left(x_{r} i_{r d}+x_{a d}\left(i_{d}+i_{f d}\right)\right) \\
0=\left(r_{r}+p x_{r}\right) i_{r d}+p x_{a d}\left(i_{d}+i_{f d}\right)-s\left(x_{r} i_{r q}+x_{a d}\left(i_{q}+i_{f q}\right)\right) \\
T_{j} p s=M_{t}-M
\end{array}\right.
$$

У рівняннях позначено у відносних одиницях: $u_{d}, u_{q}$ - проекції напруги статора на відповідні осі; $i_{d}, i_{q}$ - проекції струму статора на відповідні осі; $i_{f d}, i_{f q}$ - проекції струму збудження на відповідні осі; $i_{r d}, i_{r q}$ - проекції струму масиву ротора на відповідні осі; $s$ - ковзання генератора; $T_{j}-$ постійна часу інерції махових мас генератора та турбіни; $M$ - електромагнітний момент генератора, $M_{t}$ - момент турбіни; $r$ - активний опір обмотки статора; $r_{r}=f(s)$ - активний опір масиву ротора в функції ковзання; $r_{f}$ - активний опір обвитки збудження; $x_{r}=x_{a d}+x_{r} ; x_{a d}-$ індуктивний опір взаємоіндукції обвиток статора та ротора; $x_{r}=f(s)$ - індуктивний опір масиву ротора в функції ковзання; $x=x_{s}+x_{a d} ; x_{f s}-$ індуктивний опір розсіювання обмотки ротора; $p$ - оператор диференціювання. 3 системи рівнянь (1) видно, що параметри масиву ротора $r_{r}=f(s)$ та $x_{r}=f(s)$ функційно залежать від величини ковзання $s$ [6], що визначається ефектом витиснення струмів по поверхні бочки ротора, та мають бути представлені відповідною залежністю для розрахунку. У [6] розраховано ці параметри, але представлення результатів у дискретних значеннях не дає можливості застосування їх під час математичного моделювання. Авторами проведено аналіз наведених даних і запропоновано функцію означених характеристик вигляду:

$$
r_{r} / s=A_{r}+B_{r} /|s| ; \quad x_{r}=A_{x}+B_{x} /|s| ;
$$

де $R_{r}$ та $X_{r}$ - активний та реактивний опори масиву ротора, в.о.; $A_{r}, B_{r}, A_{x}, B_{x}$ - сталі коефіцієнти, які можна отримати в результаті апроксимації відомим методом найменших квадратів. Такі вирази доволі легко використовувати в системі рівнянь для математичного моделювання асинхронних режимів роботи АСТГ. Об'єктом розрахунку було обрано турбогенератор типу АСТГ потужністю 1000 МВт із двофазною концентричною двошаровою обвиткою на роторі.

Система рівнянь (1) наведено для варіанта врахування одного контуру масиву ротора, хоча у найбільш узагальненому випадку масив ротора може моделюватися нескінченною кількістю таких контурів, і кількість контурів можна обгрунтувати заздалегідь. Для аналізу усталених режимів роботи, а саме, для асинхронного режиму врахуємо один загальний контур масиву ротора і перейдемо до комплексної площини з нехтуванням ЕРС ковзання та приймаючи $p s=0$ :

$$
\begin{aligned}
& -\overline{\boldsymbol{U}}=r \overline{\boldsymbol{I}}+j\left(x \overline{\boldsymbol{I}}+x_{a f}\left(\overline{\boldsymbol{I}}_{f}+\overline{\boldsymbol{I}}_{r}\right)\right) ; \\
& \overline{\boldsymbol{U}}_{f}=r_{f} \overline{\boldsymbol{I}}_{f}-j s\left(x_{f} \overline{\boldsymbol{I}}+x_{a f}\left(\overline{\boldsymbol{I}}+\overline{\boldsymbol{I}}_{r}\right)\right) ; \\
& 0=r_{r} \overline{\boldsymbol{I}}_{r}-j s\left(x_{r} \overline{\boldsymbol{I}}+x_{a f}\left(\overline{\boldsymbol{I}}_{f}+\overline{\boldsymbol{I}}\right)\right),
\end{aligned}
$$

де $\overline{\boldsymbol{U}}, \overline{\boldsymbol{U}}_{\mathrm{f}}-$ напруга статора та збудження генератора відповідно; $\overline{\boldsymbol{I}}, \overline{\boldsymbol{I}}_{\mathrm{f}}, \overline{\boldsymbol{I}}_{\mathrm{r}}-$ струми статора, збудження і роторного контуру відповідно. В рівняннях (2)-(5) курсивом позначено комплексні величини. У випадку роботи генератора в асинхронному режимі із закороченими обвитками ротора рівняння (3) набуває вигляду:

$$
\boldsymbol{0}=r_{f} \overline{\boldsymbol{I}}_{f}-j s\left(x_{f} \overline{\boldsymbol{I}}+x_{a f}(\overline{\boldsymbol{I}}+\overline{\boldsymbol{I}})\right)
$$




\section{К. Б. Покровський, О. І. Маврін, В. П. Олійник}

Отже, в результаті простих перетворень, отримано систему лінійних рівнянь асинхронного режиму АСТГ з урахуванням залежних від ковзання генератора параметрів масиву ротора. Отриману систему рівнянь можна розв'язати будь-яким з доступних методів, зокрема відомим методом Гаусса. Автори розробилии алгоритм та побудовано математичну модель розрахунку усталених асинхронних режимів асинхронізованого турбогенератора потужністю 1000 МВт. Результати розрахунків асинхронні характеристики АСТГ-1000 наведено на рис. 1.

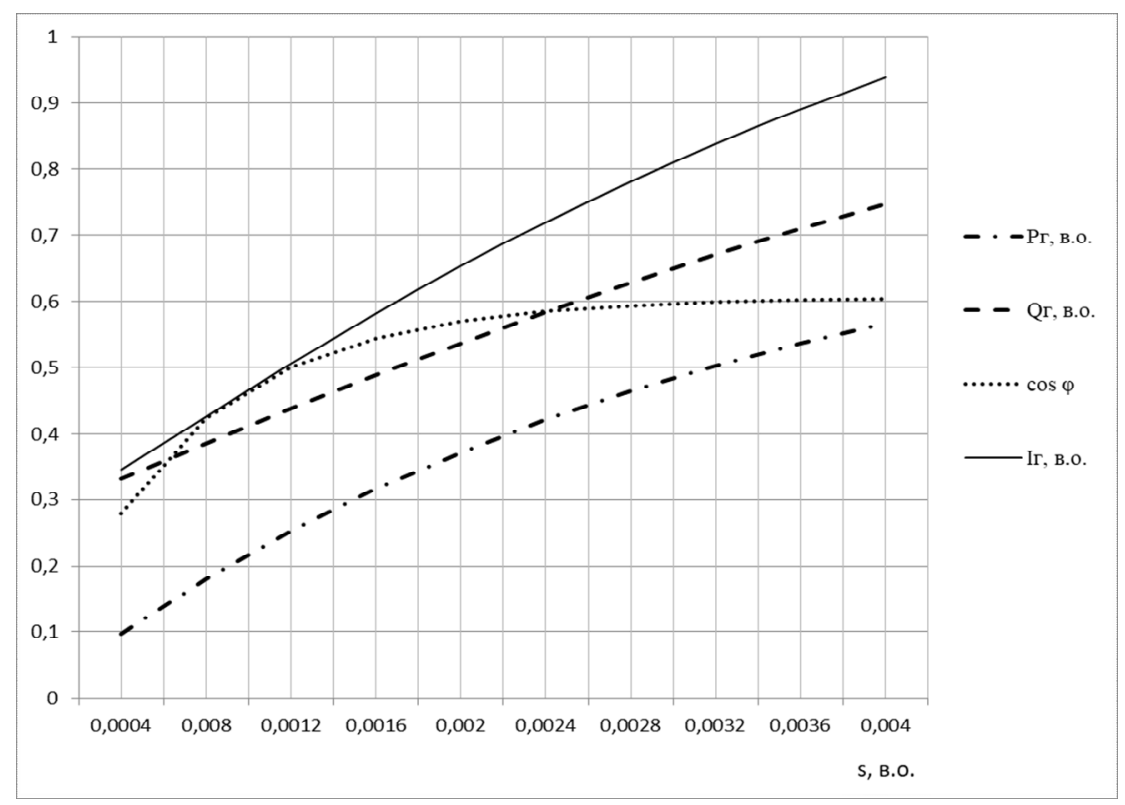

Рис. 1. Асинхронні характеристики АСТГ потужністю1000 МВт

На рис. 1 показано: $\mathrm{P}_{\mathrm{r}}, \mathrm{Q}_{\mathrm{r}}, \mathrm{I}_{\mathrm{r}}$-активна та реактивна потужність генератора та струм статора у відносних одиницях (в.о.) відповідно, $\cos \varphi$ - коефіцієнт потужності, s - ковзання ротора генератора. Наведені характеристики отримано для незмінної величини напруги статора $U=1,0$ в.о.

Результати демонструють можливість АСТГ досягати активної потужності за максимальних значень струму статора $\mathrm{P}=0,55 \ldots 0,6$ в.о. Для оцінювання такого результату врахуємо новітні і перспективні режими роботи блоку № 2 ХАЕС електричною потужністю 1000 МВт щодо добового регулювання потужності блоку [7]. Успішне проведення дослідної експлуатації блоку № 2 ХАЕС в режимі добового регулювання потужності енергоблоку за зниження навантаження до 75 \% дозволяє успішно застосовувати на такому блоці АСТГ-1000 в асинхронному режимі за незначного розширення зниження активної потужності. Застосування цих режимів позитивно впливає на режими енергосистеми під час нічних провалів навантаження, знижує навантаження на теплові електростанції в частині участі в добовому регулюванні, знижувати витрати палива на пускові та перехідні режими ТЕС.

\section{Висновки}

На основі рівнянь стану узагальненого електромеханічного перетворювача отримано систему рівнянь для розрахунку координат усталених асинхронних режимів асинхронізованого генератора потужністю 1000 МВт 3 двофазною двошаровою обвиткою на роторі. Отримано асинхронні характеристики турбогенератора за номінальної напруги статора. Результати показують, що АСТГ-1000 в асинхронному режимі може нести тривале активне навантаження у діапазоні до $\mathrm{P}=0,55 \ldots 0,6$ в.о., при цьому зміна споживаної реактивної потужності сягає до $\mathrm{Q}=0,78 \ldots 0,8$ в.о., а $\cos \varphi$ лежить у межах $0,28 \ldots 0,6$. Такі характеристики дасать змогу розглядати можливість застосування асинхрон- 
ного режиму потужного асинхронізованого генератора в умовах енергоблоку АЕС за умови розширення добового регулювального діапазону обладнання блоку.

\section{Список використаних літературних джерел}

1. Zozulin Yu. V., Antonov O. E., Bychik V. M., Borychevskyj A. M., Kobzar K.O., Livshits O.L., Rakogon V. G., Rogovyi I. H., Khaimovich L. L., Cherednik V. I.. Creation of new types and modernization of existing turbogenerators for thermal power plants: [monograph] . Harkiv.: Collegium, 2011. 223 p. (Rus).

2. Zdanovsky V. G., Minyaylo A. S., Krivyj V.V. Experience of operation of the asynchronous ASTG-200 turbogenerator. Power plants. 1993. No 1.p. 37-41.(Rus).

3. Segeda M. S., Pokrovsky K. B., Mavrin O. I., Oliynyk V. P. Modeling of power bridge modes Ukraine EU. Pratsi Instytutu Elektrodynamiky Natsionalnoi Akademii Nauk Ukrainy. Kyiv, 2010. No 52. 2019 p. 17-21 (Ukr)._DOI: https://doi.org/10.15407/publishing2019.52.017.

4. Pokrovskyi K., Muzychak A., Mavrin O., V. Olijnyk. Analysis of modes of asynchronized generator in extra-high voltage power grid. Energy Engineering and Control Systems, 2019, Vol. 5, No. 2, pp. 57-65. DOI: https://doi.org/10.23939/jeecs2019.02.057.

5. Seheda M., Minyailo O., Pokrovskyy K. Limitations in the economic distribution of reactive power between the generators. Przeglad Elektrotechniczny. 2013. No 89(6). P.299-300. ISSN-0033-2013.

6. Postnikov I. M., Asanbaev V. N., Fink A. F., Saratov W. A., Cheremisov I. Ya., Zozulin Yu. V., Karpman D. B. Investigation of parameters and characteristics of powerful asynchronous turbogenerators in asynchronous mode. [Preprint AN of Ukraine, Institute of electrodynamics; 399]. Kiev. 1984. 42 p. (Rus).

7. Glushenkov R. S. Research of key aspects of introduction of a mode of daily regulation of capacity at the NPP of Ukraine. Technological audit and production reserves. № 2/1 (22), 2015, p. 18-26. DOI:

https://doi.org/10.15587/2312-8372.2015.41404.(Rus)

\section{Список використаних літературних джерел}

1. Zozulin Yu. V., Antonov O. E., Bychik V. M., Borychevskyj A. M., Kobzar K.O., Livshits O.L., Rakogon V. G., Rogovyi I. H., Khaimovich L. L., Cherednik V. I.. Creation of new types and modernization of existing turbogenerators for thermal power plants: [monograph] . Harkiv.: Collegium, 2011. 223 p. (Rus).

2. Zdanovsky V. G., Minyaylo A. S., Krivyj V.V. Experience of operation of the asynchronous ASTG-200 turbogenerator. Power plants. 1993. No 1.p. 37-41.(Rus).

3. Segeda M. S., Pokrovsky K. B., Mavrin O. I., Oliynyk V. P. Modeling of power bridge modes Ukraine EU. Pratsi Instytutu Elektrodynamiky Natsionalnoi Akademii Nauk Ukrainy. Kyiv, 2010. No 52. 2019 p. 17-21 (Ukr)._DOI: https://doi.org/10.15407/publishing2019.52.017.

4. Pokrovskyi K., Muzychak A., Mavrin O., V. Olijnyk. Analysis of modes of asynchronized generator in extra-high voltage power grid. Energy Engineering and Control Systems, 2019, Vol. 5, No. 2, pp. 57-65. DOI: https://doi.org/10.23939/jeecs2019.02.057.

5. Seheda M., Minyailo O., Pokrovskyy K. Limitations in the economic distribution of reactive power between the generators. Przeglad Elektrotechniczny. 2013. No 89(6). P.299-300. ISSN-0033-2013.

6. Postnikov I. M., Asanbaev V. N., Fink A. F., Saratov W. A., Cheremisov I. Ya., Zozulin Yu. V., Karpman D. B. Investigation of parameters and characteristics of powerful asynchronous turbogenerators in asynchronous mode. [Preprint AN of Ukraine, Institute of electrodynamics; 399]. Kiev. 1984. 42 p. (Rus).

7. Glushenkov R. S. Research of key aspects of introduction of a mode of daily regulation of capacity at the NPP of Ukraine. Technological audit and production reserves. № 2/1 (22), 2015, p. 18-26. DOI:

https://doi.org/10.15587/2312-8372.2015.41404.(Rus) 
K. Pokrovskyi

Lviv Polytechnic National University, Department of електроенергетики та систем управління Email: kostiantyn.b.pokrovskyi@lpnu.ua

\author{
O. Mavrin \\ Lviv Polytechnic National University, \\ Department of електроенергетики та систем управління \\ Email: olherd.i.mavrin@lpnu.ua \\ V. Olijnyk \\ Lviv Polytechnic National University, \\ Department of електроенергетики та систем управління \\ Email: volodymyr.p.oliinyk@lpnu.ua
}

\title{
STATIC CHARACTERISTICS OF A POWERFUL ASYNCHRONIZED TURBOGENERATOR IN ASYNCHRONOUS MODE
}

\author{
(C) Pokrovskyi K., Mavrin O., Olijnyk V., 2020
}

The current state of the energy system of Ukraine is characterized by extensive use power lines with voltage classes of 330 and $750 \mathrm{kV}$. The charging power of such lines is quite significant, which generates significant amounts of reactive power in the network, which manifests itself especially in the hours of reducing the load in the power system with significant increases in voltage levels. Excess reactive power affect the modes of excitation regulators of synchronous generators narrowing their working range. Under such conditions, the modernization or reconstruction of power plants should take into account the possibility of solving a range of tasks related to the rationalization of electricity and energy consumption, taking into account the relationship of power plant modes with power consumers, which is associated with excess reactive power on bus bars depending on the role of the station in the power system, increasing the reliability of the station equipment, increasing the station limit of dynamic stability, reducing the required emergency reserve of the power system, etc. In this case, the problem of using power plants along with traditional synchronous generators and asynchronized turbine generators becomes relevant, which increases the reliability and quality of power plant due to greater efficiency of the asynchronized generator with stability and additional margin for reactive power consumption.

Widespread introduction of asynchronized turbine generators in the Ukrainian power system can solve the problem of excess reactive power on power plant tires during hours of load reduction in the power system due to the possibility of deep consumption of surplus asynchronized generators, which will stabilize within acceptable voltage levels.

Additionally, it should be noted that the widespread adoption asynchronized generators will affect the issue of narrowing the control range of automatic excitation regulators of synchronous generators, which in conditions of excessive reactive power reluctantly goes to work close to the consumption of reactive power synchronous generator and limited protection effect.

The results of calculations of coordinates of asynchronous modes of the asynchronized generators on the basis of parameters of the substitute scheme are resulted in work. The peculiarities of the coordinates of asynchronous modes are shown - asynchronous characteristics of an asynchronized generator with a capacity of $1000 \mathrm{MW}$. Such characteristics allow consider the possibility of applying the asynchronous mode of a powerful asynchronized generator in the conditions of the NPP power unit under the condition of expanding the daily control range of the unit equipment.

Keywords: asynchronized generator, asynchronous mode, reactive power, generator mode. 